\section{STAT3 and SOCS3 expression patterns during murine placenta development}

\author{
S. San Martin, ${ }^{1}$ J.S. Fitzgerald, ${ }^{2}$ M. \\ Weber, ${ }^{2}$ M. Párraga, ${ }^{1}$ T. Sáez, ${ }^{1}$ T.M. Zorn, ${ }^{3}$ \\ U.R. Markert ${ }^{2}$
}

Biomedical Research Centre, School of Medicine, Universidad de Valparaiso, Valparaiso, Chile; ${ }^{2}$ Placenta Lab

Department of Obstetrics,

University Hospital Jena, Germany;

${ }^{3}$ Laboratory of Reproductive and

Extracellular Matrix Biology, Institute of Biomedical Sciences, University

of Sao Paulo, Sao Paulo, Brazil

\section{Abstract}

Signal transducers and activators of transcription 3 (STAT3) has been identified as an important signal transducer in the invasive phenotype of the trophoblasts cells in in vitro studies. However, the in situ distribution and patterns of expression of this molecule in trophoblast cells during the development of the placenta are still under-elucidated. Mice uteri of gestational ages between 7 and 14 days of pregnancy (dop) were fixed in methacarn and processed with immunoperoxidase techniques for detection of STAT3 and its phosphorylation at serine (p-ser727) residues, as well as the suppressor of cytokine signaling 3 (SOCS3) expression. STAT3 was observed at 7 through 9 dop in both the antimesometrial and mesometrial deciduas, while continued immunoreactivity between 10 and 13 dop was seen only in the mesometrial decidua. In the placenta, STAT3 was detected in the cytotrophoblast cells of labyrinth and giant trophoblast cells between 10 and 14 dop. Immunoreactivity for STAT3 was also seen in trophoblast cells surrounding the maternal blood vessels. On days 10 and 11 of pregnancy, p-ser727 was detectable in the mesometrial decidua and in giant trophoblasts, while during 12-14 dop in the spongiotrophoblast region. In addition, SOCS3 was immunodetected in maternal and placental tissues, principally in the giant trophoblast cells during the whole period of the study. The present in situ study shows the distribution of STAT3, its serine activation and SOCS3 in different maternal and fetal compartments during murine placental development, thus further supporting the idea that they play a role during physiological placentation in mice.

\section{Introduction}

Trophoblast function during implantation and placentation is essential for reproduction in mammals. Some fertility impairments or obstetric pathologies are due to a molecular level dysfunction at the materno-fetal interphase. If these alterations occur during the initial steps of pregnancy, a number of pathologies with severe consequences for pregnancy and the future development of the organism may follow..$^{1-3}$

The basic phases of trophoblast differentiation and placental development are common among species that have haemochorial placentation, such as rodents, non-human primates, and humans. ${ }^{4}$ In rodents, placentation begins with trophoblast cell proliferation, which then forms the ectoplacental cone. The cone-derived cells then differentiate to form the labyrinth, the spongiotrophoblast layer, and the giant cell compartment. These structures constitute the foetal interface with the maternal decidua. ${ }^{4-7}$ Recently, a correlation between regulation of trophoblast functions and intracellular Stat signalling has been demonstrated. A member of this family, Signal transducers and activators of transcription 3 (STAT3), can be activated by a variety of growth factors and cytokines, which, via specific receptors, induce its phosphorylation and translocation into the nucleus. This process culminates with the transcription of several genes ${ }^{8,9}$ leading to an invasive trophoblast phenotype. ${ }^{10}$

The involvement of STAT3 in the regulation of the invasive phenotype of trophoblast and choriocarcinoma cells has been confirmed by RNA interference in in vitro experiments. ${ }^{11}$ Furthermore, the regulation of this transduction pathway depends on leukaemia inhibitory factor (LIF). ${ }^{12,13}$ On the other hand, LIF is present in the endometrium during implantation and decidualisation, suggesting a molecular interplay between uterus and embryo that appears to be necessary for the establishment of the maternal-fetal interface. Besides the existent knowledge concerning the regulation and activity of STAT3 in the trophoblast cell in in vitro experiments, it is little known whether these molecules and their activating signals emerge in situ during the process of trophoblastic invasion and initial placental development. Since LIF- or STAT3-deficiency leads to either infertility per implantation failure or early pregnancy loss in the murine model, much work has been dedicated to LIF and STAT3 signalling of the early pre- and postimplantation period of the mouse,${ }^{14}$ especially in terms of decidualisation. However,
Correspondence: Dr. Sebastian San Martin, Facultad de Medicina, Universidad de Valparaiso, Chile. Hontaneda 2664, Ed. Bruno Gunther, 2do piso. 92-V Valparaiso, Chile.

E-mail: sebastian.sanmartin@uv.cl

Key words: Placenta, uterus, STAT3, mouse, decidualization of endometrium.

Acknowledgments: this study was supported by grants from DIPUV (Universidad de Valparaiso, Valparaiso, Chile; grants no.12/2006; 07/2009 and CI 05/2006). Programa de Investigación Interdisciplinario (PIA) from Comisión Nacional de Investigación en Ciencia y Tecnología (CONICYT) (Anillos ACT-73, Chile) and Programa de Cooperación Científica Internacional CONICYT (190-2009) and DAAD (German Academic Exchange Service, AleChile, contract number 50735372). The Placenta-Lab, Jena, is member of EMBIC (Embryo Implantation Control), an European Network of Excellence, supported by the European Union (supported 2004-2008; contract no. 512040). S. San Martin was supported by a fellowship from Boehringer Ingelheim Fonds, Germany (2007).

Received for publication: 10 January 2013. Accepted for publication: 23 April 2013.

This work is licensed under a Creative Commons Attribution NonCommercial 3.0 License (CC BYNC 3.0).

(C) Copyright S. San Martin et al., 2013

Licensee PAGEPress, Italy

European Journal of Histochemistry 2013; 57:e19 doi:10.4081/ejh.2013.e19

recent findings indicate that LIF and STAT3 signaling is also vital for proper placental development, mainly through control of trophoblast subset differentiation. The suppressor of cytokine signaling 3 (SOCS3), a negative regulator of STAT3, when deficient, leads to midgestational fetal demise due to placental insufficiencies secondary to maldifferentiated trophoblast subsets. It was corroborated, that this signal to differentiate was driven through LIF, since LIF receptor blockage in this model could rescue the offspring. ${ }^{15,16}$

For this reason, it was our objective to obtain information on STAT3 and its regulation pattern (serine activation of STAT3 and SOCS3) during main stages of murine placental development through in situ experiments at 7-14 days of pregnancy (dop). This information is crucial to help validate the hypotheses that regulation of the STAT3 signalling pathways in fact plays a role in regulating the phenotype and function of trophoblast cells. 


\section{Materials and Methods}

\section{Animals}

All experiments were conducted in accordance with the ethical principles of animal research adopted by the Brazilian College of Animal Experimentation. The study design was approved by the joint Ethics in Animal Research Committee of the Institute of Biomedical Sciences and the University of Sao Paulo (authorisation no. 115/2000). Fourteen female Swiss mice were obtained at 14 weeks of age from colonies maintained at the Animal Facilities of the Institute of Biomedical Sciences. The mice were housed in a temperature controlled environment $\left(21 \pm 1^{\circ} \mathrm{C}\right)$, maintained at a 12-h light/dark cycle, and given free access to tap water and standard rat food Each female was housed with a male for the purpose of copulation. The vaginal plug was observed daily, and the day on which the vaginal plug was found was considered day 1 of pregnancy (term, 20 days). The mice were weighed and sacrificed on days 7 to 14 of pregnancy.

\section{Tissue collection}

The uteri samples of each pregnant mice were removed, fixed in methacarn solution (absolute methanol, chloroform, glacial acetic acid; 6:3:1) for $3 \mathrm{~h}$ at $4^{\circ} \mathrm{C}$, and embedded in Paraplast (Oxford, St. Louis, M0, USA) at $60^{\circ} \mathrm{C}$. Sections of $5 \mu \mathrm{m}$ in thickness were cut and adhered to glass slides using $0.1 \%$ poly-LLysine (Sigma) and then dried at room temperature $\left(25^{\circ} \mathrm{C}\right)$. Prior to the immunoreaction, some samples were stained with haematoxylin and eosin for morphological studies.

\section{Antibodies}

Table 1 lists the antibodies used in the present study. All antibodies were polyclonal antibodies raised in rabbit. The antibody against STAT3 recognizes the molecule independent from the activation status and all splicing variants. The antibody against phospho STAT3 (Ser727) is specific for the respective phosphorylation site (all from Cell Signaling Technology, Danvers, MA, USA). The SOCS3 antibody recognizes any status of the molecule and was purchased from Santa Cruz Biotechnology (USA). The secondary antibody for detection was a biotin-conjugated goat anti-rabbit IgG (Rockland, Gilbertsville, PA, USA).

\section{Immunoperoxidase procedures}

Sections $(5 \mu \mathrm{m})$ were cut, deparaffinized and rehydrated. Antigen retrieval was performed by incubating the sections in $10 \mathrm{mM}$ acetate sodium buffer $(\mathrm{pH} 6.0)$ at $95^{\circ} \mathrm{C}$ for 10 min. Each of the succeeding steps was followed by a thorough rinse with PBS. All steps were performed in a humid chamber, and care was taken to avoid the desiccation of the sections. Non-specific staining was blocked by incubation with $5 \%$ of normal goat serum

Table 1. Primary antibodies used in this study.

\begin{tabular}{|c|c|c|}
\hline $\begin{array}{l}\text { Primary } \\
\text { Antibodies }\end{array}$ & Specificity & $\begin{array}{l}\text { Working } \\
\text { dilution }\end{array}$ \\
\hline $\begin{array}{l}\text { Polyclonal (cat n.9132) } \\
\text { Cell Signaling Technology, } \\
\text { Danvers, MA, USA }\end{array}$ & $\begin{array}{l}\text { Anti-STAT3 } \\
\text { (Detects endogenous } \\
\text { levels of total STAT3 protein) }\end{array}$ & $1: 50$ \\
\hline $\begin{array}{l}\text { Polyclonal (cat n.9134) } \\
\text { Cell Signaling Technology, } \\
\text { Danvers, MA, USA }\end{array}$ & $\begin{array}{l}\text { Anti-Phospho-STAT3 (Ser727) } \\
\text { (Detects endogenous levels } \\
\text { of STAT3 only when } \\
\text { phosphorylated at Ser727) }\end{array}$ & $1: 100$ \\
\hline $\begin{array}{l}\text { Polyclonal (cat n. sc9023) } \\
\text { Santa Cruz Biotechnology, } \\
\text { Dallas, TX, USA }\end{array}$ & $\begin{array}{l}\text { Anti-SOCS3 } \\
\text { (Detects amino acids } \\
87-189 \text { of SOCS3) }\end{array}$ & $1: 100$ \\
\hline
\end{tabular}

Table 2. Map of STAT3, phospho-serine STAT3 (p-ser-STAT3) and SOCS3 expression within murine uteri between gestational days 714. This table offers an overview of when and where respective protein expression is detected within gravid murine uteri.

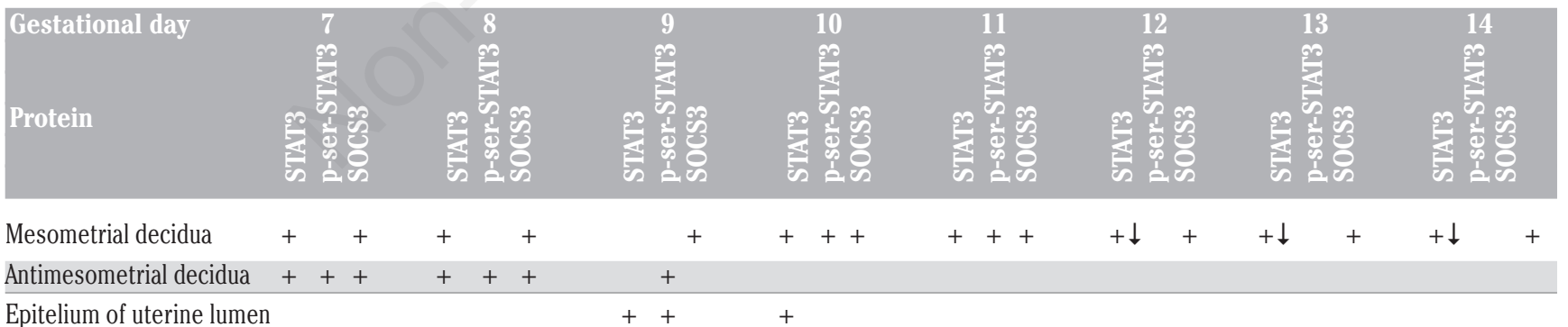

(a)

\begin{tabular}{|c|c|c|c|c|c|c|c|c|c|c|c|}
\hline Giant trophoblas & + & + & $+\uparrow$ & + & $++\uparrow$ & + & $++\uparrow$ & $+\quad+\uparrow$ & + & $+\uparrow$ & $+\uparrow$ \\
\hline Labyrinthine trophoblast & & & + & + & + & + & $+\downarrow$ & + & + & & + \\
\hline Spongio-trophoblast & & & & & + & + & $+\downarrow$ & ++ & + & + & ++ \\
\hline
\end{tabular}

Trophoblast surrounding

maternal vessels

\begin{tabular}{|c|c|c|c|c|c|c|c|c|c|}
\hline Uterine glands & $+\quad+$ & + & + & + & & & & & \\
\hline Myometrium & + & & + & & & & & & \\
\hline $\begin{array}{l}\text { Endothelium of maternal } \\
\text { vessels }\end{array}$ & + & & + & + & + & + & + & + & + \\
\hline
\end{tabular}

(a) indicates the detection in only antimesometrial region. Arrows up $(\uparrow)$ and down $(\downarrow)$ indicate the tendency of signal intensity in comparison to the earlier day. 
(Sigma)/PBS/Tween 20 for $1 \mathrm{~h}$ and $10 \mathrm{~min}$ in Cas-Block solution (Zymed Laboratories, South San Francisco, CA, USA).

Sections were incubated with the primary antibodies diluted in PBS containing 0.3\% (v/v) Tween 20, overnight at $4^{\circ} \mathrm{C}$. After extensive rinsing in PBS, all sections were incubated for $1 \mathrm{~h}$ at room temperature with biotin-conjugated goat anti-rabbit IgG, diluted 1:1000 in PBS. After rinsing in PBS, sections were incubated with Vectastain ABC kit (Vector) for $1 \mathrm{~h}$ at room temperature. Peroxidase reaction was visualised using NovaRED kit (Vector, Burlingame, CA, USA) Following immunostaining, sections were lightly stained with Mayer's haematoxylin (Merck, Darmstadt, Germany). For each immunohistochemical reaction, controls were performed by incubating the sections with normal rabbit serum or by omitting the primary antibody. Sections were examined in a Zeiss Axioskop 2 microscope, and the images were captured using a digital camera (Canon) and KS 1003.0 software (Zeiss).

\section{Results}

\section{Immunoperoxidase staining}

\section{STAT3}

On day 7 of pregnancy, STAT3 was detected in the cytoplasm and nucleus of decidual and predecidual cells, in both, antimesometrial region (Figure 1a) and mesometrial region, as well as in uterine glands (Figure 1b). Similar distribution was found on day 8 of pregnancy. On day 9, STAT3 was observed in the nucleus of giant trophoblast cells and the cytoplasm of epithelial cells of the forming new uterine lumen (Figure 1c). By day 10 of pregnancy, STAT3 was expressed in the mesometrial decidua and cells surrounding the maternal blood vessels (Figure 1d). In the antimesometrial region, STAT3 was only detectable in the epithelium of the new uterine lumen. By day 10, labyrinth (Figure 1e) and giant trophoblasts cells (Figure 1f) could be discriminated in the placenta and both were immunoreactive for STAT3. On day 11 of pregnancy, the distribution of STAT3 in the mesometrial decidua and placental regions remains similar to the previous days. Additionally, STAT3 was expressed in the spongiotrophoblast region. This pattern of immunoreaction was maintained in placentas collected on days 12 and 14 of pregnancy, however, from day 12 onwards, the immunoreaction for STAT3 decreased in the mesometrial decidua (Figure 1f).

Phospho-STAT3 (Ser727)

The phosphorylation of STAT3 at its serine727 residue was detectable from day 7 of pregnancy in the cytoplasm of decidual and predecidual cell of antimesometrial region as well as in the uterine glands. On days 8 and 9 of pregnancy, phospho-STAT3 (Ser727) is maintained in these regions (Figure 2a), whereas on day 9 , phosphorylation was also detected in the epithelium of the new uterine lumen (Figure 2b).

On day 10 and 11 of pregnancy, phosphoSTAT3 (Ser727) was detectable in the mesometrial decidua (Figure 2c) and giant trophoblasts cells (Figure 2d). On day 12 of preg- nancy, phospho-STAT3 (ser727) was found in the spongiotrophoblasts region of the placenta (Figure 2e), which was the only the positive region observed on days 13 and 14 of pregnancy (Figure 2f).

\section{SOCS3}

On day 7 of pregnancy, SOCS3 was detectable in the cytoplasm of decidual and predecidual cells, in both antimesometrial region (Figure $3 \mathrm{a}$ ) and mesometrial region, as well as in the myometrium and endothelium of maternal blood vessels (Figure $3 \mathrm{~b}$ ). In contrast
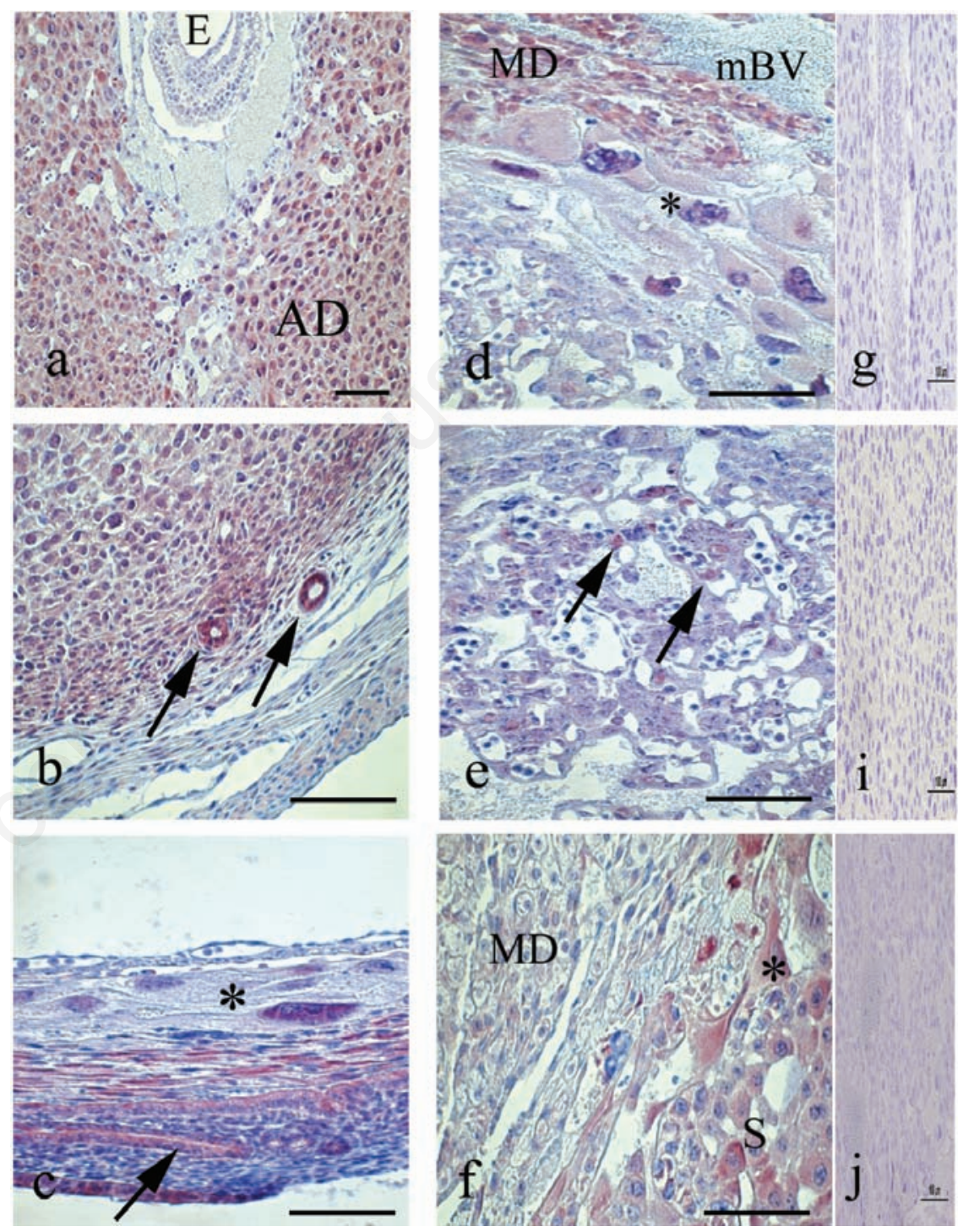

Figure 1. Immunoperoxidase staining for STAT3. a) Transversal cut of uterus on day 7 immunoreaction is evident in the decidual and predecidual cell. b) In the same day observe the immunolocalization of STAT3 in uterine glands. c) Transversal cut of uterus on day 9, show the STAT3 in the nucleus of giant trophoblast cells (asterisk), in the decidual cells and epithelium of the new light (arrow). d) In day 10, STAT3 is distributed in the placental tissues and in the mesometrial decidua (MD) and e) in the labyrinth region, STAT3 is observed in the trophoblast cells (arrows). f) In day 12, minor presences of STAT3 are observed in the mesometrial deciduas (MD), however in the placental tissues the immunoreaction is maintained. $g, h$, i) Representative negative control of immunohistochemistry. $\mathrm{AD}$, antimesometrial deciduas; $\mathrm{S}$, spongiotrophoblast region; $\mathrm{mBV}$, maternal blood vessels; *, giant trophoblast cells. Scale bar: $100 \mu \mathrm{m}$. 
to STAT3, SOCS3 was not expressed in the uterine glands. On day 8 at 10 of pregnancy, the expression of SOCS3 was maintained, similar to the previous day. Additional immunoreaction for SOCS3 was observed in the labyrinth and giant trophoblast cells (Figure 3c). From day 9 to day 14 of pregnancy, SOCS3 was detected in the mesometrial deciduas (Figure $3 \mathrm{~d}$ ), endothelium of maternal blood vessel (Figure 3e) and progressive elevation of immunoreactivity was detected in the giant trophoblast cells during these days of pregnancy (Figure 3f).

\section{Discussion}

Previous results in mice and rat showed that STAT3 activation may be important for embryo implantation and decidualisation, and may also be regulated by maternal estrogen. ${ }^{14-17}$. The first two days of our study timeline overlaps with the timeline of the Teng group, and our findings coincide. Embryo implantation and development demands a complex sequence of cellular and molecular modifications in the uterus. These include remodelling of the uterine lumen, synthesis and degradation of extracellular matrix (ECM), recruitment of immune-competent cells and an increasing vascular permeability..$^{18}$ Moreover, preceding embryo implantation, a wave of cell proliferation occurs in the endometrium and is followed by re-differentiation of endometrial fibroblasts into decidual cells; ${ }^{19}$ however, the exact mechanisms of this process continue to be poorly understood.

STAT3 have been implicated in several biological processes, such as growth, differentiation, survival and apoptosis, ${ }^{20}$ all these processes are observed during early pregnancy. The achievements of the decidual phenotype depend on several growth factors and cytokines, such as leukaemia inhibitory factor (LIF). ${ }^{21}$ This molecule is associated with the activation of STAT3 promoting the phosphorylation and nuclear translocation of STAT3 in the mouse uterus; indicating that LIF is the principal mediator of STAT3 activation in vivo. ${ }^{12}$ Since, as Teng et al. ${ }^{14}$ demonstrate, also pseudopregnant mice which decidualise their tissue, also express and activate STAT3, it can be assumed that the LIF signal at this time is not originating from the embryo. Fitzgerald $e t$ $a l .{ }^{13}$ showed that LIF elicited strong tyrosine phosphorylation and specific DNA-binding activity of STAT3 in Jeg-3 choriocarcinoma cell lines, inducing a significant acceleration of cell proliferation and promoted the capability of these cells to invade into an artificial extracellular matrix. In addition we showed that STAT3 are present in trophoblast derived cells, particularly for invasive trophoblast cells, suggesting a connection between STAT3 activity and invasiveness of trophoblast cells. The inducible suppressor of cytokine signalling (Socs) proteins, are expressed in response to cytokine stimulation of Stat phosphorylation acting in a negative-feedback mechanism to hinder the activities of cytokine receptors. ${ }^{22}$ In general, the transcription of genes encoding
SOCS3 is rapidly induced by exposure to cytokines, and SOCS3 mRNA induction appears to be dependent on the activity of STAT3. ${ }^{23}$ In our study, SOCS3 was detected in the decidua labyrinth region and the giant trophoblast cells, in a fashion the similar to STAT3 distribution. Previous study showed that in the absence of SOCS3, embryos apparently develop normally until the $10^{\text {th }}$ day of
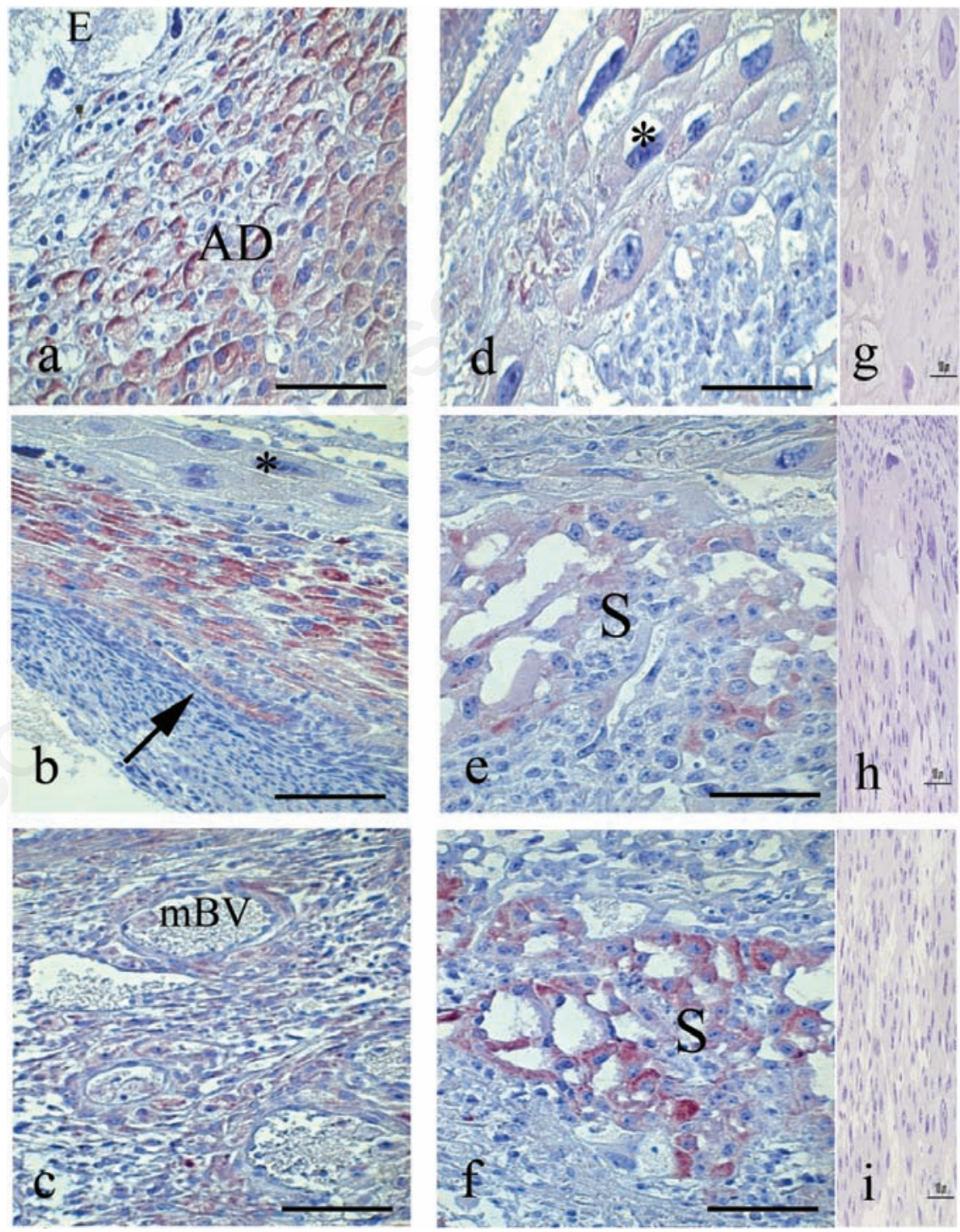

Figure 2. Immunoperoxidase staining for Phospho-STAT3 (Ser727). a) Transversal cut of uterus on day 8 , immunoreaction is strong in the cytoplasm of decidual and predecidual cell. b) This reaction continues on day 9, however immunoreaction for Serine STAT3 was not observed in the giant trophoblast cells (asterisk); arrow shows the immunoreaction in the epithelium of the new light. c) Mesometrial deciduas on day 11, show immunoreaction in this cells and surrounding the maternal blood vessels (mBV). d) In this day observe the immunoreaction in the cytoplasm of the giant trophoblast cells (asterisk). e) Spongiotrophoblast region on day 12, show immunoreaction. (f): This reaction increase on days 13 and 14. g, h, i) Representative negative control of immunohistochemistry. AD, antimesometrial deciduas; $S$, spongiotrophoblast region. Scale bar: $100 \mu \mathrm{m}$. 
pregnancy, but died between days 11 and 13 , where the formation of spongiotrophoblast and the morphogenesis of the labyrinth are affected. ${ }^{15}$

Takahashi et al. ${ }^{16}$ did one in situ hybridization staining at placentas from E9.5, show SOCS3 was expressed in all trophoblast lineage including the trophoblast stem cell population in ectoplacental cone, chorion and pri- mary giant cells. This is in correlation to our results, however we observed that 12 day onward SOCS3 was detected principally associated with giant trophoblast cells. At our part, we see that SOCS3 is generated in the trophoblast subsets starting from day 8 of pregnancy. It is appealing to hypothesize, that SOCS3 expression at this time is tolerable to a certain degree, but as the demands of fetal
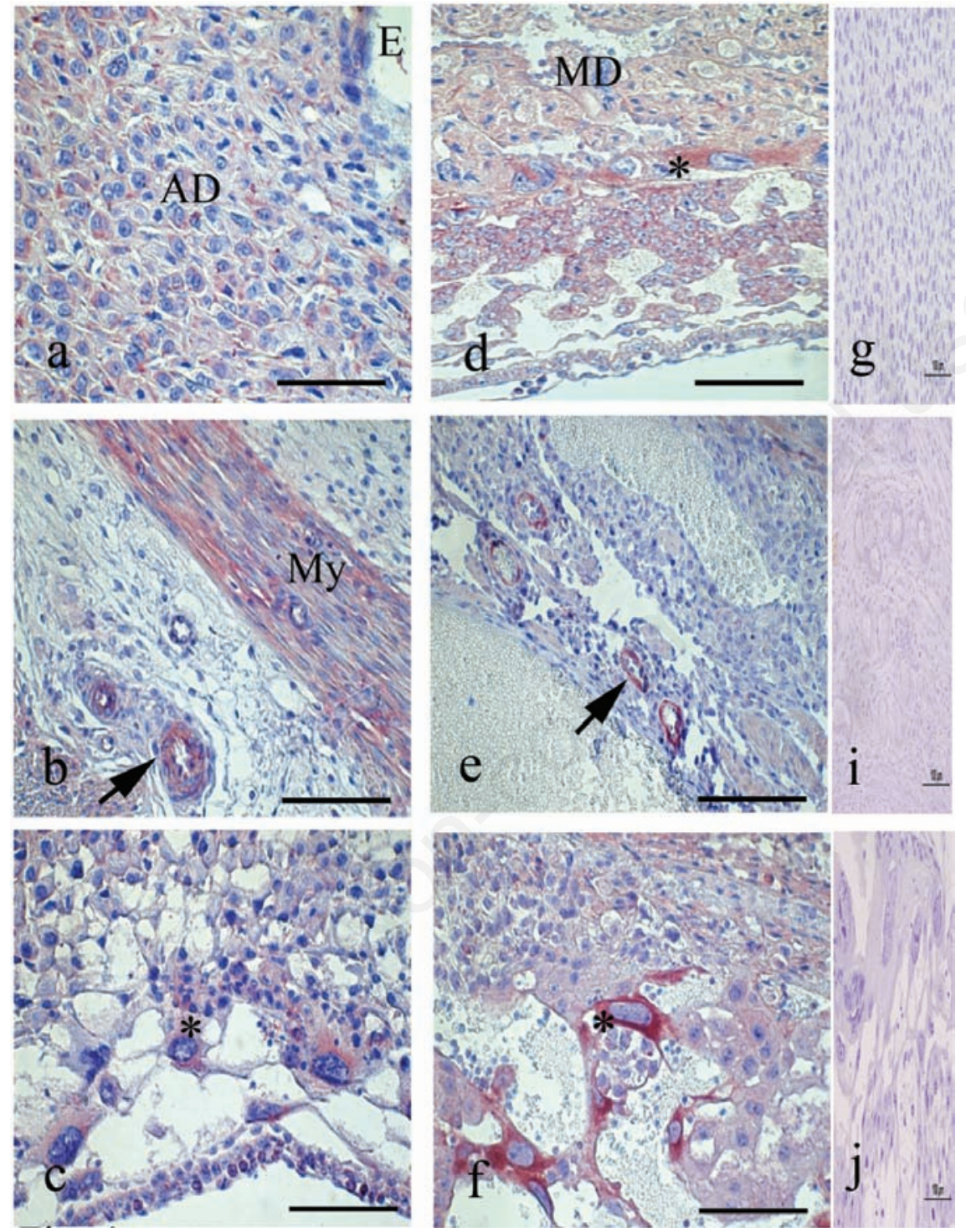

Figure 3. Immunoperoxidase staining for SOCS3. a) Transversal cut of uterus on day 7 , immunoreaction is strong in the decidual and predecidual cell. b) In the same day observe the immunolocalization of SOCS3 in myometrium (My) and blood vessels (arrow). c) Transversal cut of uterus on day 8, show the SOCS3 in the cytoplasm of giant trophoblast cells (asterisk). d) In day 10, STAT3 is distributed in the placental tissues and strongly in the giant trophoblast cells (asterisk) and mesometrial deciduas (MD); moreover e) SOCS3 are present in endothelium of maternal blood vessels (arrow). f) In day 14, the immunoreaction is maintained in several placental structures. The giant trophoblast cells showed an intense reaction (asterisk). $g, h$, i) Representative negative control of immunohistochemistry. AD, antimesometrial deciduas. Scale bar: $100 \mu \mathrm{m}$. development increases, the placental insufficiency deriving from SOCS3 deficiency cannot be compensated for longer than E13. S0CS3 modulate the Stat signal transduction ${ }^{24}$ the absence of SOCS3 can be related with the maintenance of STAT3 resulting in an altered cell function.

Another mechanism geared toward maintaining balance in the Stat and MAPK system is serine phosphorylation of STAT3. The definitive function of serine phosphorylation of STAT3 is under controversy since serine phosphorylation has been seen to both boost as well as inhibit STAT3 activity. The current paradigm is that serine phospho STAT3 interferes with tyrosine phosphorylation of Stat. Serine phosphorylation is accomplished or mediated by members of several other signalling pathway families, such as (but not exclusively) ERK, MAPK, PKCdelta, mTOR, PI3K/AKT, but there is a paucity in defining which mediators enhance and which down-regulated the transcriptional activity of this protein, and which effect it has on cell function. ${ }^{25}$ Interestingly, the serine phosphorylation of STAT3 was detected especially in the spongiotrophoblast cells of placenta starting from day 12 . Coinciding to this time, it seems that fetal demise begins. It is within the range of possibility that this further signal leads to a further activation of the ERK/MAPK pathway, possibly leading to final demise of the embryo.

Finally, the balance between the expression and activation of STAT3 and its inhibitor SOCS3 could be essential for decidualisation and normal placental development in mice.

\section{References}

1. Jauniaux E, Burton GJ. Pathophysiology of histological changes in early pregnancy loss. Placenta 2005;26:114-23.

2. Lessey BA. The role of the endometrium during embryo implantation. Hum Reprod 2000;15(Suppl.6):39-50.

3. Norwitz ER. Defective implantation and placentation: laying the blueprint for pregnancy complications. Reprod Biomed Online 2006;13:591-9.

4. Enders AC, Welsh A0. Structural interactions of trophoblast and uterus during hemochorial placenta formation. J Exp Zool 1993;266:578-87.

5. Cross JC. Genetic insights into trophoblast differentiation and placental morphogenesis. Semin Cell Dev Biol 2000;11:105-13.

6. Muntener M, Hsu YC. Development of trophoblast and placenta of the mouse. A reinvestigation with regard to the in vitro culture of mouse trophoblast and placenta. Acta Anat (Basel) 1997;98:241-52. 
7. Pijnenborg R, Robertson WB, Brosens I, Dixon G. Review article: trophoblast invasion and the establishment of haemochorial placentation in man and laboratory animals. Placenta 1981;2:71-91.

8. Darnell JE Jr. Phosphotyrosine signaling and the single cell:metazoan boundary. Proc Natl Acad Sci USA 1997;94:11767-9.

9. Pellegrini S, Dusanter-Fourt I. The structure, regulation and function of the Janus kinases (JAKs) and the signal transducers and activators of transcription (STATs). Eur J Biochem 1997;248:615-33.

10. Fitzgerald JS, Busch S, Wengenmayer T, Foerster K, de la Motte T, Poehlmann TG, et al. Signal transduction in trophoblast invasion. Chem Immunol Allergy 2005;88: 181-99.

11. Poehlmann TG, Fitzgerald JS, Meissner A, Wengenmayer T, Schleussner E, Friedrich $\mathrm{K}$, et al. Trophoblast invasion: tuning through LIF, signalling via STAT3. Placenta 2005;26(Suppl. A):S37-41.

12. Cheng JG, Chen JR, Hernandez L, Alvord WG, Stewart CL. Dual control of LIF expression and LIF receptor function regulate STAT3 activation at the onset of uterine receptivity and embryo implantation. Proc Natl Acad Sci USA 2001;98:8680-5.

13. Fitzgerald JS, Tsareva SA, Poehlmann TG, Berod L, Meissner A, Corvinus FM, et al.
Leukemia inhibitory factor triggers activation of signal transducer and activator of transcription 3, proliferation, invasiveness, and altered protease expression in choriocarcinoma cells. Int J Biochem Cell Biol 2005;37:2284-96.

14. Teng CB, Diao HL, Ma XH, Xu LB, Yang ZM. Differential expression and activation of STAT3 during mouse embryo implantation and decidualization. Mol Reprod Dev 2004;69:1-10.

15. Roberts AW, Robb L, Rakar S, Hartley L, Cluse L, Nicola NA, et al. Placental defects and embryonic lethality in mice lacking suppressor of cytokine signaling 3. Proc Natl Acad Sci USA 2001;98:9324-9.

16. Takahashi Y, Carpino N, Cross JC, Torres M, Parganas E, Ihle JN. SOCS3: an essential regulator of LIF receptor signaling in trophoblast giant cell differentiation. EMBO J 2003;22:372-84.

17. Teng CB, Diao HL, Ma H, Cong J, Yu H, Ma $\mathrm{XH}$, et al. Signal transducer and activator of transcription 3 (STAT3) expression and activation in rat uterus during early pregnancy. Reproduction 2004;128:197-205.

18. Abrahamsohn PA, Zorn TMT, Oliveira S. Decidua in rodents, pp. 279-293. In: Glasser SR, Aplin JD, Giudice LC, Tabibzadeh S (eds.) The endometrium. London: Taylor and Francis, 2002.
19. Abrahamsohn PA, Zorn TM. Implantation and decidualization in rodents. J Exp Zool 1993;266:603-28.

20. Chapman RS, Lourenco P, Tonner E, Flint D, Selbert S, Takeda K, et al. The role of STAT3 in apoptosis and mammary gland involution. Conditional deletion of STAT3. Adv Exp Med Biol 2000;480:129-38.

21. Shuya LL, Menkhorst EM, Yap J, Li P, Lane $\mathrm{N}$, Dimitriadis E. Leukemia inhibitory factor enhances endometrial stromal cell decidualization in humans and mice. PLoS One 2011;6:e25288.

22. Cacalano NA, Sanden D, Johnston JA. Tyrosine-phosphorylated SOCS-3 inhibits STAT activation but binds to p120 RasGAP and activates Ras. Nat Cell Biol 2001;3: 460-5.

23. Alexander WS. Suppressors of cytokine signalling (SOCS) in the immune system. Nat Rev Immunol 2002;2:410-6.

24. Krebs DL, Hilton DJ. SOCS: physiological suppressors of cytokine signaling. J Cell Sci 2000;113:2813-9.

25. Friedbichler K, Hoelbl A, Li G, Bunting KD, Sexl V, Gouilleux F, et al. Serine phosphorylation of the Stat5a C-terminus is a driving force for transformation. Front Biosci 2011;6:3043-56 